\title{
Nicotine Inhaler
}

National Cancer Institute

\section{Source}

National Cancer Institute. Nicotine Inhaler. NCI Thesaurus. Code C19977.

A device consisting of a mouthpiece and a thin, plastic cartridge that contains nicotine plug and delivers nicotine in a vapor that is absorbed in the mouth. 